\title{
The Role of Springtime Arctic Clouds in Determining Autumn Sea Ice Extent 0
}

\author{
CHRISTOPHER J. COX \\ Cooperative Institute for Research in Environmental Sciences, and NOAA/Earth System \\ Research Laboratory, Boulder, Colorado \\ TANEIL UTTAL \\ NOAA/Earth System Research Laboratory, Boulder, Colorado \\ Charles N. Long AND MatThew D. Shupe \\ Cooperative Institute for Research in Environmental Sciences, and NOAA/Earth System \\ Research Laboratory, Boulder, Colorado \\ ROBERT S. STONE \\ Science and Technology Corporation, Boulder, Colorado \\ SANDY STARKWEATHER \\ Cooperative Institute for Research in Environmental Sciences, and NOAA/Earth System \\ Research Laboratory, Boulder, Colorado
}

(Manuscript received 13 February 2016, in final form 9 June 2016)

\begin{abstract}
Recent studies suggest that the atmosphere conditions arctic sea ice properties in spring in a way that may be an important factor in predetermining autumn sea ice concentrations. Here, the role of clouds in this system is analyzed using surface-based observations from Barrow, Alaska. Barrow is a coastal location situated adjacent to the region where interannual sea ice variability is largest. Barrow is also along a main transport pathway through which springtime advection of atmospheric energy from lower latitudes to the Arctic Ocean occurs. The cloud contribution is quantified using the observed surface radiative fluxes and cloud radiative forcing (CRF) derived therefrom, which can be positive or negative. In low sea ice years enhanced positive CRF (increased cloud cover enhancing longwave radiative forcing) in April is followed by decreased negative CRF (decreased cloud cover allowing a relative increase in shortwave radiative forcing) in May and June. The opposite is true in high sea ice years. In either case, the combination and timing of these early and late spring cloud radiative processes can serve to enhance the atmospheric preconditioning of sea ice. The net CRF (April and May) measured at Barrow from 1993 through 2014 is negatively correlated with sea ice extent in the following autumn $\left(r^{2}=0.33 ; p<0.01\right)$. Reanalysis data appear to capture the general timing and sign of the observed CRF anomalies at Barrow and suggest that the anomalies occur over a large region of the central Arctic Ocean, which supports the link between radiative processes observed at Barrow and the broader arctic sea ice extent.
\end{abstract}

Supplemental information related to this paper is available at the Journals Online website: http://dx.doi.org/10.1175/ JCLI-D-16-0136.s1.

Corresponding author address: Christopher J. Cox, NOAA/ ESRL, 325 Broadway, Boulder, CO 80305.

E-mail: christopher.j.cox@noaa.gov

\section{Introduction}

Effective seasonal planning in the Arctic for safety, transportation, energy development, and resource management requires advanced seasonal forecasting of sea ice conditions. Interannual variability in sea ice extent is superimposed upon a decreasing longer-term trend in the seasonal minimum (e.g., Cavalieri and Parkinson 2012), 
and present forecasting capabilities represent the trend in sea ice significantly better than the interannual variability (Stroeve et al. 2014). Currently, within a given year, the observed sea ice extent and area are statistically predictive of the September minimum only beginning around July because the internal memory of the sea ice system is relatively short-lived (BlanchardWrigglesworth et al. 2011). Recent studies (Kapsch et al. 2013, 2014; Choi et al. 2014) indicate that the atmosphere has an important role in conditioning the sea ice properties through top-down radiative transfer of energy in April, May, and June, which affects the timing of both the melt season and how quickly ice is melted with these processes contributing to the eventual sea ice extent annual minimum. This implies that taking into account atmospheric processes can increase the predictive skill of seasonal forecasts of minimum sea ice extent at lead times of 3-5 months.

Freezing and thawing of ice are driven by perturbations to the surface energy budget, which is written as follows:

$$
F_{\text {net }}=Q_{\text {net }}+H_{s}+H_{l}+C
$$

where $F_{\text {net }}$ is the net surface flux, equal to the sum of the sensible $H_{s}$, latent $H_{l}$, subsurface $C$, and net radiative fluxes $Q_{\text {net }}$. The variable $Q_{\text {net }}$ is written as follows:

$$
Q_{\text {net }}=\mathrm{LW} \downarrow-\mathrm{LW} \uparrow+\mathrm{SW} \downarrow-\mathrm{SW} \uparrow,
$$

where LW is longwave radiation, SW is shortwave radiation, and arrows indicate downwelling $(\downarrow)$ and upwelling $(\uparrow)$ fluxes. All terms are defined here such that positive values warm the surface. When $F_{\text {net }}$ is positive, the energy content of the ice rises, and vice versa. Changes in $F_{\text {net }}$ generally translate to changes in temperature, but when the temperature reaches $0^{\circ} \mathrm{C}$ it stabilizes and additional energy exchanges go toward melting or freezing. Thus, a large amount of energy must be input into the ice prior to an observed reduction in ice volume from melt. Much of this conditioning energy originates from the atmosphere (Persson 2012).

Existing studies suggest a number of mechanisms by which the atmosphere may facilitate the conditioning of the spring sea ice. Among the suggested mechanisms are modulation of the ice-albedo feedback by clouds, increased near-surface air temperature from air masses advected from lower latitudes, and buffered surface cooling through insulation. These mechanisms increase the energy content of the ice, warming it from the top down (Persson 2012). Generally, the radiative terms are drivers of changes in $F_{s}$ while $H_{s}, H_{l}$, and $C$ are damping responses (e.g., Persson et al. 1999). Furthermore, in spring the time integral of $C$ represents a gradual increase of the storage of energy in the ice pack. Thus, we focus on the radiative terms here, and we will collectively refer to the conditioning mechanisms as atmospheric radiative preconditioning (ARP), representing variability in the $F_{s}$ modulated by the radiative effects of atmospheric temperature and humidity, clouds, surface albedo, and surface temperature. ARP differs from preconditioning associated with annual (e.g., BlanchardWrigglesworth et al. 2011) or multiannual (e.g., Parkinson and Comiso 2013) memory in the sea ice and upper ocean. The roles of turbulent $\left(H_{s}\right.$ and $\left.H_{l}\right)$ and subsurface $(C)$ flux terms, which are sometimes discussed alongside ARP (e.g., Persson 2012; Kapsch et al. 2013; Wang et al. 2015), are not considered here, nor do we focus on the physical modification of the snow and ice surface properties (e.g., Stone et al. 2002; Schröder et al. 2014) that may be associated with ARP or other mechanisms.

Choi et al. (2014) show that years with increased cloud cover in May are characterized by reduced solar radiation at the surface, damping the ice-albedo feedback and preserving sea ice. Schröder et al. (2014) indicate that modifications to the surface albedo from melt pond extent in spring also control the ice-albedo feedback and that loss of snowpack in early spring through sublimation may modify snow microphysics, potentially preconditioning snow (Stone et al. 2002, 2005). Kapsch et al. $(2013,2014)$ contend that longwave radiation dominates ARP with shortwave radiative absorption primarily acting as a feedback [a conclusion also reached with respect to snow cover by Wang et al. (2015)], and large-scale advection of warm, moist air accompanied by increased cloud cover into the western Arctic in spring is thought to be a key factor in low sea ice years (Graversen et al. 2011; Kapsch et al. 2013, 2014). This advection is from southerly flow originating in the North Pacific and passing northward into the western Arctic (generally, the Beaufort, Chukchi, and East Siberian Sea regions; e.g., Overland and Wang 2010; Graversen et al. 2011; Dong et al. 2014). Longwave radiation processes are implicated in the 2007 record melt (Graversen et al. 2011; Dong et al. 2014) and are observed to thin sea ice during spring through combined forcing from water vapor, temperature, and clouds (Francis and Hunter 2007). Both longwave radiation processes and surface albedo are tied to melt onset over the sea ice (Persson 2012). Additionally, radiative preconditioning of the sea ice affecting the growth of ice thickness is reported in winter by Liu and Key (2014) and Letterly et al. (2016). Cloud anomalies have also been found to affect the sea ice melt season during the summer months (e.g., Kay et al. 2008). While the effect of clouds is enhanced when anomalies persist by increasing the integrated effect over time, clouds are 
also observed to modulate surface melting and refreezing on the Greenland ice sheet even when the duration of anomalies are quite brief (hours) (Bennartz et al. 2013; Van Tricht et al. 2016; Solomon et al. 2016, manuscript submitted to J. Climate), and Persson (2012) finds that relatively brief and large pulses of energy into the ice associated with synoptic systems are a trigger for melt onset.

Clouds are a complicating factor. Relative to clear skies, clouds simultaneously cool the surface by reflecting shortwave radiation upward and warm the surface by emitting longwave radiation downward. The shortwave radiative cooling effect is substantially reduced over icecovered surfaces because the albedo of the surface is similar to that of the cloud and thus the net shortwave radiative absorption is similar in both cases (e.g., Curry and Ebert 1992; Miller et al. 2015). In the longwave, the radiative flux from clouds measured at the surface is directly controlled by atmospheric temperature and humidity (Cox et al. 2015) and can reach $100 \mathrm{Wm}^{-2}$ (Bennartz et al. 2013; Cox et al. 2014). The longwave radiation dominates the cloud radiative forcing (CRF) at the surface in all arctic seasons except summer, when the surface albedo decreases because of melting snow and ice (Curry and Ebert 1992; Curry et al. 1996; Intrieri et al. 2002; Dong and Mace 2003; Shupe and Intrieri 2004; Dong et al. 2010; Kay and L'Ecuyer 2013). In spring, the CRF at the surface is transitioning from net warming in the winter to net cooling in the summer. From April through June at Barrow, Alaska, the magnitude of the monthly mean shortwave CRF $\left(\mathrm{CRF}_{\mathrm{SW}}\right)$ increases, causing the loss of shortwave radiative absorption at the surface to change from $-5 \mathrm{Wm}^{-2}$ in April to $-65 \mathrm{~W} \mathrm{~m}^{-2}$ by June, while the longwave CRF $\left(\mathrm{CRF}_{\mathrm{LW}}\right)$ increases from approximately +10 to $+45 \mathrm{~W} \mathrm{~m}^{-2}$ (Dong et al. 2010). Given that the observed decadal trend in sea ice can be explained by a perturbation to the surface energy budget of only $1 \mathrm{~W} \mathrm{~m}^{-2}$ (Kwok and Untersteiner 2011), even small relative interannual variability in the CRF terms may be significant for sea ice.

Previous studies of ARP rely on reanalysis, model, and satellite datasets and thus only approximate the surface radiation budget. Radiative fluxes reported by model and reanalysis data products are known to contain biases in the Arctic (Bromwich et al. 2007; Tjernström et al. 2008; Walsh et al. 2009; Cesana et al. 2012; Cox et al. 2012; Zygmuntowska et al. 2012; Zib et al. 2012; Cox et al. 2014; Pithan et al. 2014; Wesslén et al. 2014; Lindsay et al. 2014), in particular as a result of poor representation of cloud properties, such as the amount of liquid water (Tjernström et al. 2008; Cesana et al. 2012; Bennartz et al. 2013; Wesslén et al. 2014). These biases are also likely present in the boundary conditions for model-based forecasts of sea ice, which are typically derived from reanalysis and forecast fields that use similar cloud parameterizations. The sensitivity of ARP to variability in cloud properties and the precise role of clouds in ARP processes thus remain unclear.

Here, the focus is on utilizing high-quality observations of shortwave and longwave radiative fluxes measured at the surface from observatories at Barrow, Alaska. Lagged correlations are determined between the observations of the radiative fluxes in spring and sea ice extent and concentrations in the following autumn. Then values of $\mathrm{CRF}, \mathrm{CRF}_{\mathrm{SW}}$, and $\mathrm{CRF}_{\mathrm{LW}}$ derived from the measurements are used to assess the contributions to ARP from clouds.

\section{Datasets and methodology}

\section{a. Broadband radiative fluxes and cloud radiative forcing}

Observations of the surface radiation budget (1-min temporal resolution) are from Barrow, Alaska $\left(71.32^{\circ} \mathrm{N}\right.$, $\left.156.61^{\circ} \mathrm{W} ; 8 \mathrm{~m}\right)$. Measurements are available from two locations separated by approximately $1 \mathrm{~km}$. The focus station for this work is operated by NOAA as an atmospheric baseline observatory. Both longwave and shortwave radiation data are available for this station beginning in late April 1993 (note that this timing limits the representativeness in spring 1993); these measurements are also archived with the global Baseline Surface Radiation Network (BSRN; Ohmura et al. 1998). When possible and necessary, data gaps are filled using observations from the DOE Atmospheric Radiation Measurement (ARM) Program broadband radiation suite, which was installed in spring 1998. Annual mean observations from the two stations are comparable to within $1.5 \mathrm{Wm}^{-2}$, which is within the expected uncertainty of the measurements (Dong et al. 2010). However, the albedo tends to remain high beneath the ARM station for a longer period of time in spring because of drifting snow building up in greater amounts near the ARM station compared to the NOAA station; this causes some discrepancies in the upwelling fluxes between the stations in June (Dong et al. 2010). For a thorough discussion of the uncertainties in the NOAA and ARM radiation measurements at Barrow, refer to Dong et al. (2010).

Observations are quality controlled first by visual inspection and then processed by an automated procedure described by Long and Shi (2008). SW $\downarrow$ values are a blended product that combines global SW $\downarrow$ with diffuse $\mathrm{SW} \downarrow$ plus direct SW $\downarrow$ fluxes, with the sum used whenever possible to mitigate measurement uncertainty associated with low solar elevation angles. The resulting 
quality-controlled Barrow radiation datasets for $\mathrm{LW} \downarrow$, $\mathrm{LW} \uparrow, \mathrm{SW} \downarrow$, and $\mathrm{SW} \uparrow$ are each $93 \%$ complete or better for the period 1993-2014, though it is important to note that frost and rime problems are common in the Arctic and difficult to screen out (e.g., Matsui et al. 2012). In addition to removal of suspect data, the data were also processed to correct for infrared loss in the downwelling shortwave radiative measurements as recommended by Dutton et al. (2001) and Younkin and Long (2003).

In addition to the measured fluxes, higher-order metrics derived from the data are analyzed, including $\mathrm{CRF}_{\text {Sw }}$ (Long and Ackerman 2000; Long 2005), CRF LW $_{\text {W }}$ (Long 2005; Long and Turner 2008), and scattered cloud cover (SCV) (Long et al. 2006).

CRF is defined as the difference between the observed all-sky net flux and an estimation of net flux under clear skies (e.g., Ramanathan et al. 1989), where

$$
\begin{aligned}
& \mathrm{CRF}_{\mathrm{LW}}=(\mathrm{LW} \downarrow-\mathrm{LW} \uparrow)-\left(\mathrm{LW}_{\mathrm{CLR}} \downarrow-\mathrm{LW}_{\mathrm{CLR}} \uparrow\right), \\
& \mathrm{CRF}_{\mathrm{SW}}=(\mathrm{SW} \downarrow-\mathrm{SW} \uparrow)-\left(\mathrm{SW}_{\mathrm{CLR}} \downarrow-\mathrm{SW}_{\mathrm{CLR}} \uparrow\right),
\end{aligned}
$$

and

$$
\mathrm{CRF}=\mathrm{CRF}_{\mathrm{LW}}+\mathrm{CRF}_{\mathrm{SW}} .
$$

A detailed description of the methodology used to calculate the clear-sky terms in Eqs. (3) and (4) for Barrow and associated uncertainties can be found in Dong et al. (2010) and references therein. To obtain continuous estimates of $\mathrm{LW} \uparrow_{\mathrm{CLR}}$ necessary for the present study, some modifications were made to the Dong et al. (2010) method as described in detail in the supplementary material. Note that since the CRF calculations are tied directly to the measurements at all times, uncertainties in the base measurements that could potentially affect trend analyses, such as from changes in instruments or calibration coefficients, subtract out in Eqs. (3) and (4) because those uncertainties are anchored to the clear-sky terms.

Hourly averages of CRF, $\mathrm{CRF}_{\mathrm{LW}}$, and $\mathrm{CRF}_{\mathrm{Sw}}$ are calculated from the 1-min dataset (with at least $30 \mathrm{~min}$ of data required for each average). While there is only a small amount of missing data in the NOAA time series, a complete time series is important for the present analysis. For times when the ARM data are not available to fill these gaps, those longer than 1 day are filled using the climatological mean and data gaps smaller than 1 day are filled by linear interpolation.

One-minute-average SCV $\left(160^{\circ}\right.$ field of view centered on zenith) is calculated using SW $\downarrow_{\text {CLR }}$ and all-sky SW $\downarrow$ global, diffuse, and direct fluxes (Long et al. 2006). The calculation relies on an empirical power law relationship established between the SCV observed using sky imagers and the diffuse shortwave radiation enhancement caused by clouds, normalized by SW $\downarrow_{\text {CLR }}$. Results compare to observations to within 10\% RMSE (Long et al. 2006). When the shortwave radiation observations are unavailable an effective fractional sky cover calculated from LW $\downarrow$ (Durr and Philipona 2004; Long and Turner 2008) is used instead; this calculation is lower than that derived from the shortwave radiation data (by about $6 \%$ at Barrow) because the SCV derived from the longwave radiation measurements is only weakly sensitive to cold, tenuous clouds (e.g., thin cirrus); the bias is removed by scaling to agree with the shortwave radiative calculation. Fractional cloud cover (FCC) is calculated from SCV by averaging SCV in time.

\section{b. Sea ice}

Calculations of monthly average sea ice extent $\left(\mathrm{km}^{2}\right)$ are from the National Snow and Ice Data Center (NSIDC) sea ice index dataset, beginning in November 1978 (Fetterer et al. 2002). High and low sea ice years are defined by monthly mean September sea ice extent from the NSIDC over the period of study from 1993 through 2014. High years (1996, 2001, 2013, and 2014) and low years $(1994,1995,2007$, and 2012) are defined as falling outside plus or minus one standard deviation $( \pm 1 \sigma)$ of the linearly detrended 1993 through 2014 anomaly (over the study period the trend is approximately linear).

The reference dataset for spatially resolved sea ice concentration is the Hadley Centre Sea Ice and Sea Surface Temperature dataset (HadISST; Rayner et al. 2003). HadISST provides monthly mean sea ice concentrations in $1^{\circ}$ by $1^{\circ}$ grid cells beginning in 1870 (only data corresponding to the 1993-2014 study period are used here). In the HadISST dataset, sea ice concentrations are parameterized by an empirical relationship with sea surface temperature, which is determined using surface and satellite observations. HadISST has been used previously in similar studies (Choi et al. 2014).

\section{c. Reanalysis data}

Reanalysis fields are from the European Centre for Medium-Range Weather Forecasts (ECMWF) interim reanalysis (ERA-Interim; Dee et al. 2011), acquired from the ECMWF data archive (http://apps.ecmwf.int/ datasets/). ERA-Interim uses a four-dimensional variational data assimilation (4D-Var) system operating at 12-h intervals on an N128 reduced Gaussian grid (data are archived on a $0.75^{\circ}$ latitudinal-longitudinal grid). ERA-Interim has been used previously in similar studies (Kapsch et al. 2013, 2014; Wang et al. 2015). Though ERA-Interim radiation fields contain biases in the Arctic (Zygmuntowska et al. 2012; Cox et al. 2012, 2014; 

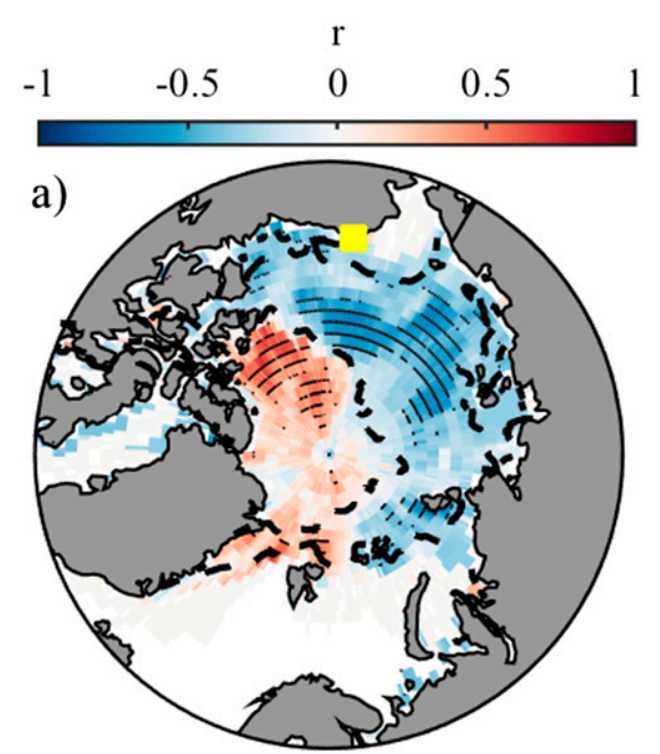

FIG. 1. (a) Correlation coefficient $r$ between the April-May anomaly in downwelling all-wave radiative flux measured at Barrow and the sea ice concentration (SIC) for the following September in each grid cell of HadISST, 1993-2014. Regions of negative correlation indicate that positive anomalies measured in spring at Barrow were followed by negative anomalies in SIC. Black dots mark grid cells where the correlation is statistically significant $(p<0.05)$. (b) Standard deviation in September mean SIC in each grid cell of the HadISST dataset from 1993 to 2014. The yellow square in both panels is the location of Barrow. The dashed-black line in both panels is the $20 \%$ standard deviation contour line for SIC displayed in (b).

Wesslén et al. 2014), its performance is an improvement upon earlier-generation reanalyses (Cox et al. 2012), and differences in spatial representation between observations and gridded data contribute to reported biases (Cox et al. 2014).

$\mathrm{CRF}$ is calculated from ERA-Interim using net allsky and net clear-sky fluxes, which are provided by ECMWF as products. The northward vector of the vertically integrated total energy transport field $J$ $\left(\mathrm{W} \mathrm{m}^{-1}\right)$ is also calculated by ECMWF as a product and is used in this study:

$$
J=\frac{1}{g} \int_{0}^{1} v\left(\frac{1}{2} \mathbf{v} \cdot \mathbf{v}+L q+c_{p} T+\varphi\right) \frac{\partial p}{\partial \eta} d \eta
$$

where $g$ is the gravitational constant, $v$ is the meridional wind velocity, $\mathbf{v}$ is the horizontal wind velocity vector, $c_{p}$ is the specific heat of moist air, $L$ is the specific heat of condensation, $q$ is the specific humidity, $T$ is temperature, $p$ is pressure, $\varphi$ is the geopotential, and $\eta$ is the hybrid sigma-pressure vertical coordinate (Simmons and Burridge 1981).

\section{Results}

\section{a. Spatial distributions of lagged correlation}

By averaging ERA-Interim fields of the surface energy budget over the region where interannual variability in sea ice concentrations is large, Kapsch et al. (2013) showed that the net energy into the surface in April and May is negatively correlated with the amount of sea ice in the following September and reported that this is driven primarily by perturbations to LW $\downarrow$ caused by clouds. Analogously, perturbations to absorbed solar radiation facilitated by clouds and derived at the top of the atmosphere from satellite data were implicated in modulating sea ice extent in September beginning in May by Choi et al. (2014).

Figure 1a shows that a similar relationship is also captured between the observed downward all-wave flux anomaly ( $\left.\mathrm{LW} \downarrow^{\prime}+\mathrm{SW} \downarrow^{\prime}\right)$ at Barrow averaged over April and May and each grid point in HadISST in the following September. Significant correlations $(p<0.05$; dots in Fig. 1a) are observed over a large portion of the region where interannual variability in sea ice concentrations within HadISST grid cells was large during the study period, shown in Fig. 1b. These correlations also appear in the same general regions as those reported by Kapsch et al. (2013) and Choi et al. (2014) and are consistent with the hypothesis that years with higherthan-average incoming radiative fluxes at the surface in spring are associated with lower-than-average sea ice concentrations in September.

It is not surprising that observations from Barrow carry this information because an important pathway for advection into the Arctic that affects sea ice in spring is 


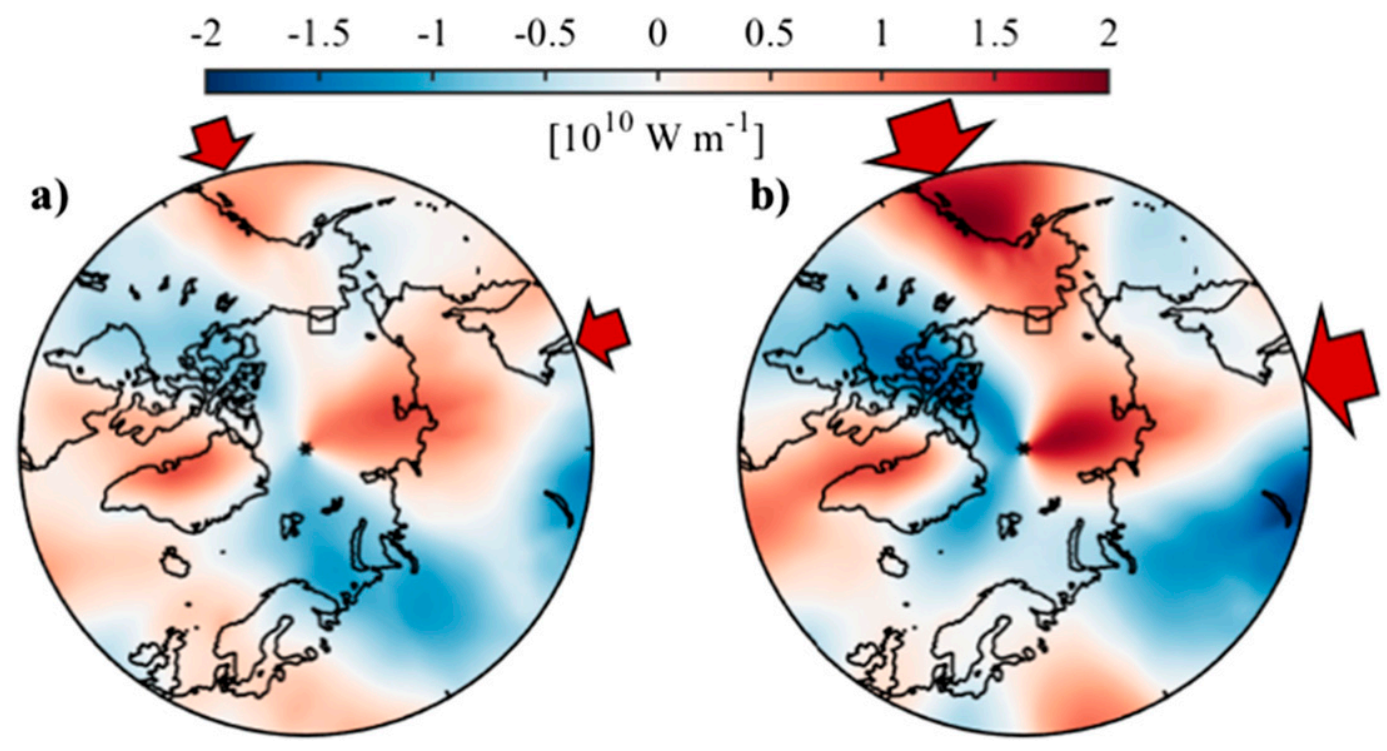

FIG. 2. The mean vertically integrated northward vector of the total energy transport $\left(\mathrm{W} \mathrm{m}^{-1}\right)$ from April to May in (a) high sea ice years and (b) low sea ice years. Red (positive values) indicates transport into the Arctic from the south, and blue (negative values) indicates exit from the Arctic to lower latitudes.

thought to be from the North Pacific (e.g., Graversen et al. 2011), passing first over the region near Barrow and then over the sea ice before exiting over the northern Canadian archipelago and the Fram Strait (Fig. 2). Note that since the relationships shown in Fig. 1a are also sensitive to the amount of interannual variability in the sea ice at each grid point, a precise determination of the spatial representation would benefit from a different metric, such as melt onset (see, e.g., Stone et al. 2005). Note also that correlation is observed in regions of the Arctic quite distant from Barrow, which may be caused by spatial autocorrelation in the sea ice. Some positive correlations are also observed in Fig. 1a over the central ice pack. As can be seen from Fig. 1b, these correlations represent variability in sea ice concentrations of just a few percent and may reflect increased compaction in the central ice pack during low years.

\section{b. The transition in CRF from winter to summer at Barrow}

The seasonal cycle in CRF in the Arctic is described by many studies (e.g., Curry and Ebert 1992; Curry et al. 1996; Intrieri et al. 2002; Dong and Mace 2003; Shupe and Intrieri 2004; Dong et al. 2010; Kay and L'Ecuyer, 2013; Miller et al. 2015), but it is important here to examine the controlling factors for some of the subtle variations in the CRF transition from winter to summer observed at Barrow.

Figure 3 shows the daily mean CRF averaged for all 22 years in the record at Barrow (black) from 1 January through 31 July. To illustrate how the transition in CRF from winter to summer occurs, the time series is plotted alongside that of $\mathrm{CRF}_{\mathrm{LW}}$ (red), $\mathrm{CRF}_{\mathrm{SW}}$ (blue), albedo (dashed cyan), the cosine of the solar zenith angle (SZA; dashed purple), and monthly mean FCC (dotted yellow). In winter, CRF is completely controlled by $\mathrm{CRF}_{\mathrm{LW}}$, but in March as the sun begins to rise, CRF decreases as clouds act to cool the surface in the shortwave radiation proportionally to the amount of available sunlight (e.g., Curry et al. 1996). This cooling is relatively weak owing to the snow-covered surface, which has a high albedo (e.g., Curry and Ebert 1992). Then, from March through April, increases in FCC, which are typical at Barrow during spring (see also Dong et al. 2010; Shupe et al. 2011), increase the CRF via $C_{R F}$. The effect of the increasing FCC is enhanced by the near-surface temperature increase outpacing the water vapor response, enabling more longwave radiative flux from each cloud to influence the surface (Cox et al. 2015). Note that the magnitude of $C R F_{S w}$ and $C R F_{L W}$ are both tens of watts per square meter in May, so while the CRF generally dominated by the longwave radiation at this time, it may be modulated significantly by either longwave or shortwave radiation. The increase in CRF is then abruptly cut off by rapidly decreasing albedo in late May-early June as the seasonal snowmelt occurs, causing $\mathrm{CRF}_{\mathrm{Sw}}$ to drop from about -20 to about $-100 \mathrm{~W} \mathrm{~m}^{-2}$ over the course of just a few days. The local maximum in CRF that is observed in April and May, which is the main focus of the present study, is thus predominantly controlled by FCC, atmospheric temperature and humidity, and available sunlight along its leading edge and by the timing of 


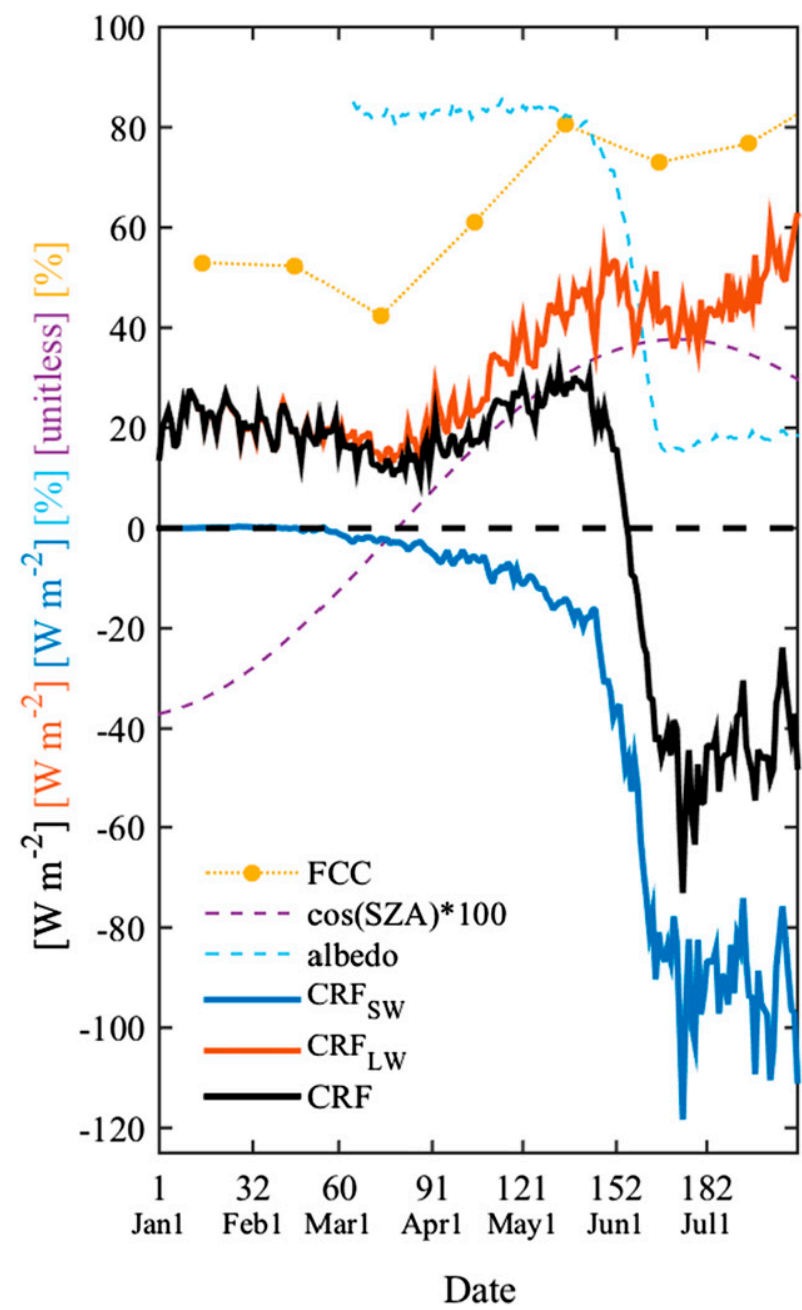

FIG. 3. Daily mean 1993-2014 CRF (black; $\mathrm{W} \mathrm{m}^{-2}$ ), $\mathrm{CRF}_{\mathrm{SW}}$ (blue; $\mathrm{W} \mathrm{m}^{-2}$ ), $\mathrm{CRF}_{\mathrm{LW}}\left(\mathrm{red} ; \mathrm{W} \mathrm{m}^{-2}\right)$, surface albedo (\%; dashed cyan $)$, cosine of the SZA $(\times 100$; dashed purple $)$, and monthly mean FCC (\%; dotted yellow).

snowmelt on its trailing edge. Importantly, changes in the contributions from longwave and shortwave radiative effects are already occurring prior the first appearance of persistently negative CRF.

\section{c. The role of clouds in ARP}

In Fig. 4a, the CRF mean seasonal cycle (smoothed with a 21-day running mean) and absolute variability are shown for low sea ice years in red and high sea ice years in blue; the average for all years is shown in black. When examining the difference between low and high sea ice years, the time period between the beginning of April and the end of June is notable for the presence or lack of the springtime local maximum in CRF described in the previous section. This is particularly pronounced in April and May when the surface is still covered by snow at Barrow. The consequence of this local maximum is that during a spring that precedes an autumn with anomalously low sea ice extent, CRF is considerably higher than during a spring that precedes an autumn with anomalously high sea ice extent. As indicated in the discussion of Fig. 3, the increase in CRF is maintained by different processes in early spring than late spring. Enhanced $\mathrm{CRF}_{\mathrm{LW}}$ in Fig. $4 \mathrm{~b}$ is needed in early spring (when the sun is still low) to maintain positive CRF while in late spring, positive CRF in Fig. 4 is maintained by damped $\mathrm{CRF}_{\mathrm{SW}}$ (Fig. 4c; when the sun is higher). Thus, in comparing Figs. $4 \mathrm{~b}$ and $4 \mathrm{c}$, the timing of the separation between low and high years is seen to occur earlier for $\mathrm{CRF}_{\mathrm{LW}}$ and later for $\mathrm{CRF}_{\mathrm{SW}}$.

Recall that the CRF is modulated both by properties of the clouds and by properties of the environment wherein the clouds reside (e.g., surface cover). Nevertheless, the local maximum in CRF during spring appears to be supported by variability in cloud properties rather than surface cover. This is evidenced by a recalculation of CRF using only the downwelling components of Eqs. (3) and (4), thus removing the surface from the equation (i.e., removing the surface temperature response to clouds in the LW and the influence of surface albedo in the SW); this metric is termed the cloud radiative effect (CRE; e.g., McFarlane et al. 2013). CRE is plotted for longwave CRE ( $\left.\mathrm{CRE}_{\mathrm{LW}}\right)$ in Fig. $4 \mathrm{~d}$ and for shortwave CRE $\left(\mathrm{CRE}_{\mathrm{Sw}}\right)$ in Fig. 4e. Several characteristics of the CRE plots are notable: First, there is little difference between longwave CRF and CRE but a large difference between the shortwave components. This demonstrates that for variability in CRF that is not directly tied to cloud properties, albedo is the variable most important to the present discussion. Second, the low and high sea ice years separate similarly to that observed in Fig. 4a, indicating that the difference in the CRF local maximum between low and high sea ice years can be attributed to clouds rather than interannual variability in properties of the surface. Third, the timing of the CRE perturbations, especially in early spring, are similar and opposite in sign between longwave and shortwave components, highlighting the importance of the high-albedo surface in early spring in supporting the CRF local maximum caused by clouds (and manifested as the offsetting separation in Figs. $4 \mathrm{~b}$ and $4 \mathrm{c}$, respectively).

The difference in the CRF seasonal cycle at Barrow between low and high sea ice years from Fig. 4a appears to be characterized not only by more positive (or less negative) CRF but also by a later transition to negative CRF. Recall from Fig. 3 that April through June also spans the snowmelt period at Barrow and that the reduction in albedo from the exposed ground beneath the 

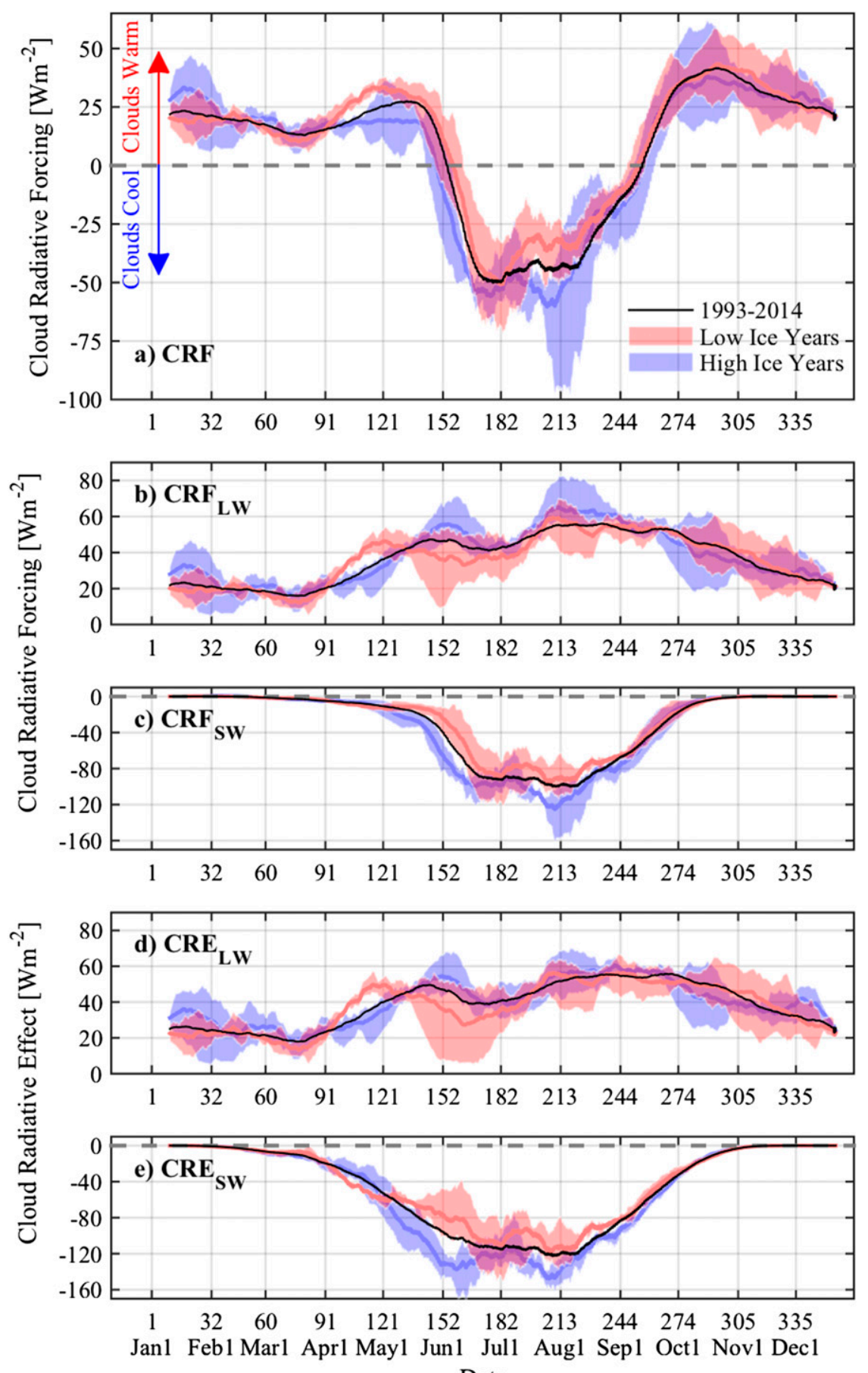

FIG. 4. (a) Hourly average CRF at Barrow smoothed with a 21-day boxcar filter, 1993-2014 (black). Low ice years are red, and high ice years are blue. Shading represents the absolute variability of the four low and high years, respectively. (b)-(e) As in (a), but for (b) $C_{R F}$, (c) $\mathrm{CRF}_{\mathrm{SW}}$, (d) $\mathrm{CRE}_{\mathrm{LW}}$, and (e) $\mathrm{CRE}_{\mathrm{SW}}$. Note that the dataset begins in late April 1993; thus, January-April 1993 are not represented. 
snow is the dominant annual perturbation to CRF at that location. Interestingly, it is the low sea ice years (presumably representing enhanced melt) that have later melt dates in the sample shown in Fig. 4. It is reasonable to assume that the surface cover before melting is similar between Barrow and the Arctic Ocean (e.g., Riihelä et al. 2013), but it is not after. Thus, it is important to separate the influence of the atmospheric and cloud properties from the surface cover influence on the CRF such that the time period during which the surface albedo at Barrow is similar to the sea ice region to the north of Barrow can be isolated for analysis.

As previously described, the results in Figs. $4 d$ and $4 \mathrm{e}$ support the interpretation that the main differences between low and high sea ice years observed at Barrow in Fig. 4a are due to atmospheric properties rather than variability in surface cover. This is further supported by the fact that the first date of snow-free conditions at Barrow is uncorrelated with sea ice extent throughout the Arctic in the following September (not shown). This lack of relationship should not be confused with the relationship between the first snow-free date at Barrow and melt onset over the sea ice in the Beaufort and Chukchi Seas, which was established by Stone et al. (2005). To explain the relationship between the first snow-free date at Barrow and sea ice concentrations, additional considerations need to be taken into account, such as spatial variability in subsurface fluxes and precipitation. Furthermore, it is possible that the cloud anomalies for the subset of high and low sea ice years express a causal relationship between CRF and enhanced melt but that associated increased cloud cover in early spring in low sea ice years could potentially result in a deeper snowpack. If deeper snow did occur in spring in years with low sea ice extents, it would take longer to melt, thereby extending the net warming supported by clouds later into June over land. If this additional snow also were to occur over the sea ice proper, it may provide additional insulation in early spring preventing the ice from growing as thick (Hezel et al. 2012), thus permitting more rapid melting.

The first date of snow-free conditions at Barrow is between day of year (DOY) 144 (24 May) and 166 (15 June) during the study period, and no trend is detectable over this time period [note that a significant trend is observed toward earlier melt dates in the long term record, beginning in the 1960s (Stone et al. 2002)]. Typically, the duration of the melt period is less than one week; thus, we set DOY 137 (DOY 144 minus 1 week) to be the last date when CRF at Barrow can be confidently attributed to cloud anomalies rather than interannual variability in surface cover. Using this as the end date, we calculate the average CRF for each year from DOY
91 (1 April) through DOY 137 (17 May) and correlate it with September sea ice extent for all 22 years in the data record; the results are shown in Fig. 5.

Figure 5 shows that the CRF anomaly during spring is negatively correlated with the sea ice extent the following September $(p<0.01)$, capturing approximately $33 \%$ of the variance in the September sea ice extent. In the figure, both time series are detrended; thus the relationship represents interannual variability. For context, the relationship is still highly significant $\left(r^{2}=0.3\right.$; $p<0.01$ ) when the time period over which the CRF anomaly is averaged is extended through mid-June. Upon closer examination, there are several aspects of Fig. 5 that are notable. First, no years are observed in the bottom-left or top-right quadrants of Fig. 5, suggesting that when the CRF is above average at Barrow in spring, there is high confidence that an extreme above-average sea ice extent will not be recorded during the following September, and vice versa. Second, distributions of large positive CRF anomalies (1998, 2003, and 2010) and large negative CRF anomalies (1997, 1999, 2000, 2002, and 2004) corresponding to typical (detrended) September sea ice extents are seen in Fig. 5. A closer analysis of these years using ERA-Interim fields reveals that temperature, humidity, and northward energy transport anomalies (not shown) are consistent with those during the extreme sea ice years that appear with CRF anomalies of similar values. The difference is that the large CRF anomalies for the years with typical (detrended) September sea ice extent (both positive and negative) are dominated by $\mathrm{CRF}_{\mathrm{LW}}$ throughout the spring with very little deviation from the average appearing in the $\mathrm{CRF}_{\text {Sw }}$ (not shown). The main cause of this is persistent FCC anomalies, but the relative lack of signal in the $\mathrm{CRE}_{\mathrm{SW}}$ suggests that other properties of the clouds may also be different. This result reinforces the importance of the respective roles of both longwave and shortwave radiation in modulating $A R P$.

Since the results in Fig. 5 span the time period during which seasonal transitions are occurring in both $\mathrm{CRF}_{\mathrm{SW}}$ and $\mathrm{CRF}_{\mathrm{LW}}$, the timing of anomalies during a given season is likely important for determining the influence of clouds on the surface. We thus examine the individual daily average anomalies of $\mathrm{SW} \downarrow, \mathrm{LW} \downarrow, \mathrm{CRF}_{\mathrm{LW}}$, and $\mathrm{CRF}_{\text {SW }}$ for years with low September sea ice extent (Fig. 6a) and high September sea ice extent (Fig. 6b) as well as FCC and CRF in Figs. 6c and 6d. Low sea ice years are characterized by a positive anomaly in $\mathrm{LW} \downarrow$ in April, which is associated with increased cloud cover. This is similar to what is reported by Kapsch et al. (2013). Unlike Kapsch et al. (2013), but consistent with Choi et al. (2014), the positive April anomaly is followed by a positive anomaly in $\mathrm{SW} \downarrow$ (corresponding to a weak 


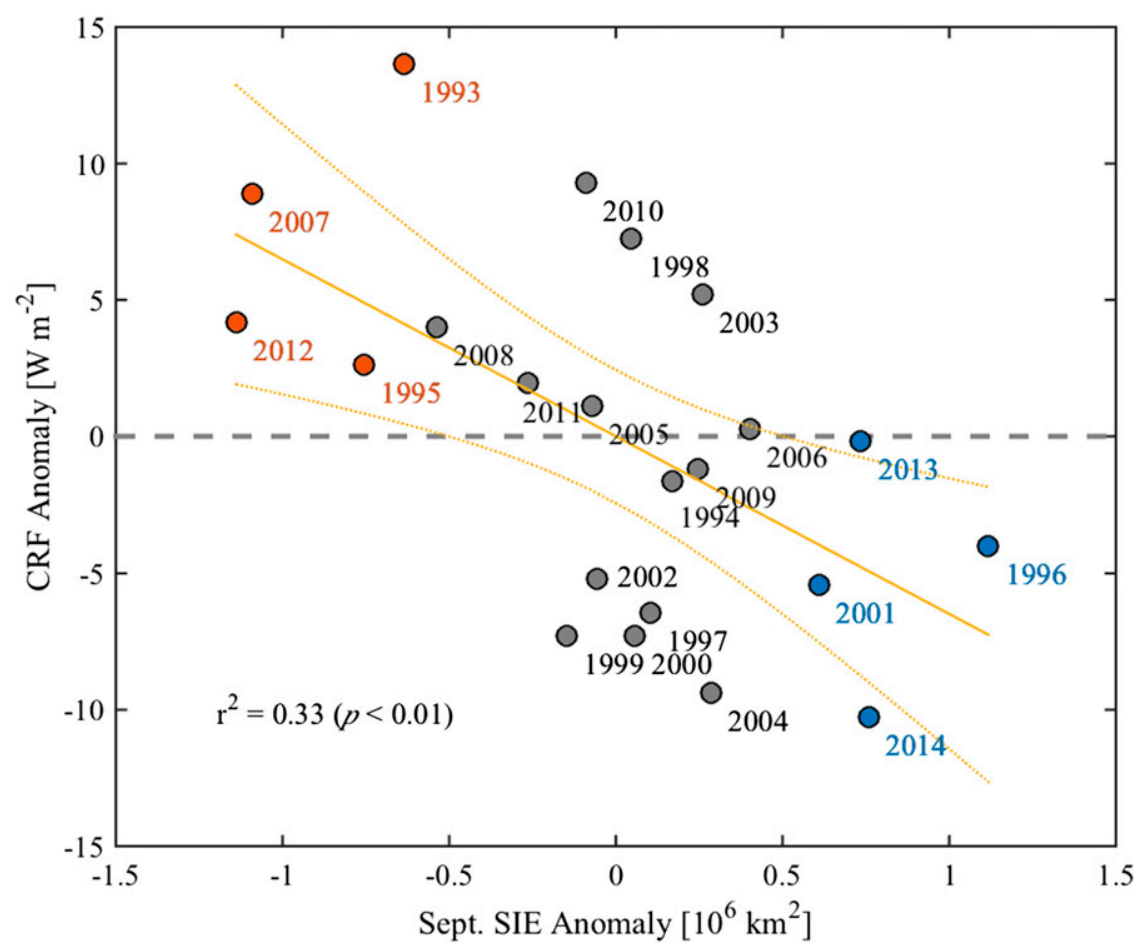

FIG. 5. Linearly detrended CRF anomaly (yellow line) at Barrow calculated as the average anomaly from DOY 91 through DOY 137 in each year ( $y$ axis) vs the detrended September sea ice extent (SIE) anomaly, 1993-2014 ( $x$ axis). Red-filled circles are the four identified low sea ice years, and the blue-filled circles are the four identified high sea ice years in the study period. Note that 1993 (red-filled circle with CRF anomaly equal to about $+14 \mathrm{~W} \mathrm{~m}^{-2}$ ) may be a poor estimate of the CRF for that spring because the full suite of instrumentation was not installed until late April 1993. If spring of 1993 is omitted, the statistical relationship changes to $r^{2}=0.29$ $(p=0.01)$.

negative anomaly in LW $\downarrow$ ) in May and June associated with decreased cloud cover. Both of these observations are consistent with the CRF time series plotted in Fig. 4. High sea ice years are characterized by the opposing anomalies to low years. If the timing of the positive cloud anomaly is early in spring, the clouds reduce surface cooling, retaining energy at the surface at a time when the shortwave radiative cooling from clouds is weak because of low sun angles and high surface albedo. However, if it is later this effect may be counterbalanced or exceeded by the increasing shortwave radiative cooling due to clouds. When the cloud anomalies are opposing between early and late spring, as in these extreme sea ice years, the result in the CRF anomaly is either persistently positive or persistently negative from April through early June. The time period for the transition (at Barrow) from Figs. 4 and 6 is the first two weeks of May.

Since cloud properties are the key ingredient in modulating the local maximum in CRF observed in the spring in low sea ice years (Figs. 4 and 6), we will now examine the statistical significance of the cloud-cover anomaly. Figure 7a shows the monthly mean FCC for the low (blue) and high (red) sea ice years. Consistent with Figs. 4 and 6, the FCC in low sea ice years compared to the high sea ice years is relatively high in April and then relatively low in May and June. The relationship between FCC and September sea ice extent is plotted in Fig. $7 \mathrm{~b}$ for both April (blue) and 15 May through 30 June (green) for the full 1993-2014 record (15 May is chosen to capture the time period after the transition reported in the previous paragraph). When the difference between the FCC in April and May-June (May-June minus April) is plotted (purple in Fig. 7b), the relationship becomes more robust $\left(r^{2}=0.32 ; p=0.01\right)$. Thus, the combination of the opposing early and late spring anomalies is more important than the occurrence of one or the other.

\section{Discussion and conclusions}

From previous work (Graversen et al. 2011; Kapsch et al. 2013), evidence from reanalyses indicates that anomalies in southerly flow from the North Pacific in 




FIG. 6. From DOY 80 (21 Mar) through 181 (30 Jun), (a) anomalies $\left(\mathrm{W} \mathrm{m}^{-2}\right.$ ) of LW $\downarrow$ (blue), SW $\downarrow$ (red), CRF $\mathrm{SW}_{\mathrm{SW}}$ (yellow), and $\mathrm{CRF}_{\mathrm{LW}}$ (purple) for low sea ice years. (b) As in (a), but for high sea ice years. (c) CRF (W m ${ }^{-2}$; green), FCC $\left(\%\right.$; cyan), and near-surface air temperature $\left(T_{a}\right.$, dark red; $\left.{ }^{\circ} \mathrm{C}\right)$ for low sea ice years. (d) As in (c), but for high sea ice years. All data are hourly averages smoothed by a 21-day boxcar filter.

early spring accompanied by increased cloud cover are tied to interannual variability in autumn sea ice extent. The clouds, temperature, and humidity constructively enhance delivery of radiative energy from the atmosphere to the surface at a critical time of year, thereby preconditioning the melt season prior to substantial exposure of ocean and land surface by seasonal ice melt. Here, we show direct observations of the surface radiation budget that support this finding.

Our results also extend previous findings by exploring in more detail how clouds facilitate ARP. Since $\mathrm{CRF}_{\mathrm{SW}}$ and $\mathrm{CRF}_{\mathrm{LW}}$ are transitioning seasonally in spring, the timing of cloud anomalies is important in determining whether or not they support melting or preservation of ice early in the melt season. Our results are in agreement with Choi et al. (2014), who show a positive correlation between cloud cover in May and sea ice in September. However, Choi et al.'s (2014) results are apparently in contradiction to those from Kapsch et al. (2013), who report enhanced LW $\downarrow$ and reduced SW $\downarrow$ throughout the spring in low sea ice years. The results presented here help resolve this discrepancy by demonstrating two things: First, that timing is the key factor, even prior to the exposure of lower albedo surfaces by melting ice and snow; specifically, Kapsch et al.'s (2013) findings may be more sensitive to early season anomalies while Choi et al.'s (2014) study focused only on late spring anomalies. Second, while the anomalies that were the focus of Kapsch et al. (2013) or Choi et al. (2014) may be influential without the occurrence of the other, when both occur at the right time in the same spring, the influence is magnified, and it is in these years that the extreme high and low September sea ice extents are generally observed.

We find that the average CRF from the beginning of April through mid-to-late May, which is prior to the first snow-free date in all years at Barrow (thus, the surface albedo is high during this time in all years), is 

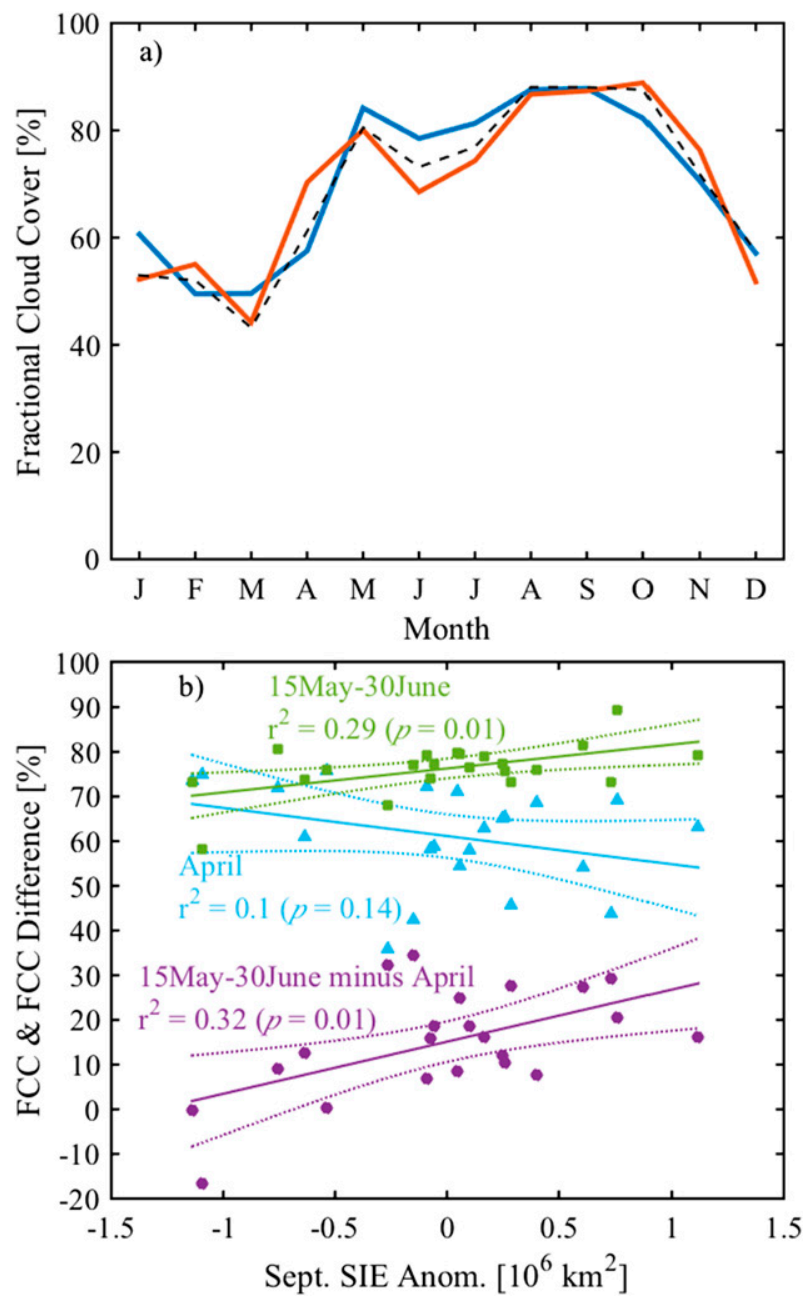

FIG. 7. (a) Monthly mean FCC at Barrow (1993-2014; dashed black line) calculated from 1-min temporal-resolution SCV observations, which are derived from broadband radiative fluxes as described in section 2a. The red line in (a) is the mean for the low sea ice years, and blue line in (a) is the mean for the high sea ice years. (b) Relationships between the detrended SIE anomaly in September and FCC for April (blue), from 15 May to 30 Jun (green), and the difference between the two (May-June minus April; purple).

significantly $(p<0.01)$ negatively correlated with the sea ice extent in the following September over the 22-yr record, accounting for approximately $33 \%$ of the variance in the minimum sea ice extent. Positive anomalies in CRF throughout the spring are made possible by a combination of increased cloud cover (more longwave radiative cloud warming) in early spring when shortwave radiative cloud cooling is negligible followed by decreased cloud cover in late spring when shortwave radiative cooling by clouds dominates. Thus, increased cloud warming in April followed by decreased cloud cooling in May appears to be an important signal foreshadowing low sea ice years. The opposite anomalies are observed to occur in spring during years that experience higher than average sea ice conditions.

An important observation from Fig. 5 is that CRF anomalies of similar direction and magnitude to those of extreme sea ice years are sometimes observed in years that have average (relative to the detrended time series) September sea ice extent. Recall that these anomalies are controlled by $\mathrm{CRF}_{\mathrm{LW}}$ rather than in combination with $\mathrm{CRF}_{\mathrm{SW}}$. This implies that the mechanisms producing the anomaly are just as important as the anomaly itself, which may signal the role of feedbacks. $\mathrm{CRF}_{\mathrm{LW}}$ is always dominant in early spring. However, if $\mathrm{CRF}_{\mathrm{SW}}$ is responsible for a positive CRF anomaly late in spring, the ice-albedo feedback is enhanced (clearer skies), but if $\mathrm{CRF}_{\mathrm{LW}}$ is responsible then the ice-albedo feedback is damped (cloudier skies) and the opposite is also true. Consequently, the magnitude and sign of the springtime CRF anomaly alone is only sufficient to rule out one or the other sea ice extreme (i.e., the empty quadrants in Fig. 5), while detailed knowledge of the timing, sign, and magnitude of $\mathrm{CRF}_{\mathrm{LW}}$ and $\mathrm{CRF}_{\mathrm{SW}}$ in April and May is more useful in predicting the sea ice extent in the following September.

Given this, we hypothesize a conceptual model for the role of clouds in ARP as follows: low sea ice years are preceded by a positive anomaly in CRF throughout spring with the CRF anomaly in late spring caused by clearer skies, which enhance the ice-albedo feedback. Alternatively, for high sea ice years, low CRF occurs throughout spring, maintained in late spring by increased cloud cover, which damps the ice-albedo feedback. While this model should not be interpreted as absolute, it is consistent with the fundamental understanding of the seasonal cycle in CRF found in the literature (refer to section 3b).

In this study, we focus on a single location (Barrow) chosen because of its long surface-based observational record positioned in what may be a significant pathway for advecting energy into the Arctic during the critical time of year for preconditioning the ice. The important spring transition in longwave and shortwave cloud radiative effects is dependent on solar zenith angle and thus latitude. Barrow's latitude is at the southerly extent of the sea ice and therefore the timing for this transition could be later in the year over the sea ice to the north of Barrow (see also Kay and L'Ecuyer 2013). This might be a relevant factor in one of the key differences between our findings and those from Kapsch et al. (2013), who show the dominance of longwave radiation extending later into the spring than the early part of May implied by the present study. Note also that the study period in Kapsch et al. (2013) begins in 1979 whereas the 



FIG. 8. CRF anomaly $\left(\mathrm{W} \mathrm{m}^{-2}\right.$ ) over the ocean from ERA-Interim north of $60^{\circ} \mathrm{N}$ for (a) low sea ice years in April, (b) low sea ice years in May, (c) high sea ice years in April, and (d) high sea ice years in May. In all panels the square is the location of Barrow; the color of the square corresponds to the same color scale as the reanalysis, but with reference to the observations from Barrow. Red indicates positive CRF anomalies, and blue indicates negative CRF anomalies.

present study begins in 1993, and thus not all of the same extreme years are included in the analyses. Nonetheless, the CRF over the majority of the arctic basin reported by ERA-Interim (Fig. 8) is broadly consistent with the measurements from Barrow, showing above-average CRF in both April and May in low sea ice years and the opposite for high sea ice years. Indeed, $\mathrm{CRF}_{\mathrm{LW}}$ and $\mathrm{CRF}_{\text {SW }}$ anomalies reported by ERA-Interim for these months are also generally consistent with the observed results from Barrow, as are the magnitudes of the anomalies in all three metrics. We acknowledge that the relative roles of biases in contributing to this result are uncertain because it is difficult to distinguish biases in the reanalysis fields from those that may be associated with the limited spatial sampling of the observations. These biases likely affect the timing of the dominance of the longwave versus shortwave cloud radiative effects, and if compensating biases are present, they may not drastically influence the total CRF.

Some interesting features that appear in Fig. 8 are isolated regions of particularly large CRF anomalies that are not necessarily in the same direction as the anomalies over much of the central Arctic (e.g., east of Greenland and the North Pacific between Alaska and Russia). These regions are likely anomalous because of interannual differences in sea ice concentrations in contrast to the central Arctic, which is ice covered in all years in April and May (i.e., these differences are caused 
by interannual variability in surface albedo rather than cloud anomalies). Figure 8 provides some qualitative evidence for general agreement with the results from Barrow and reinforces the interpretation from Fig. 4 that in the context of this study, the fluxes observed at Barrow are representative of a large region of the Arctic. This is consistent with previous studies that have sought to contextualize Barrow spatially and report that Barrow generally represents the atmospheric signal for a large region of the far-western Arctic (Dong and Mace 2003; Stone et al. 2005; Dong et al. 2010; Shupe 2011; Shupe et al. 2011; Cox et al. 2012).

Finally, it may be possible to capitalize on the observed springtime CRF and radiation relationships examined here to develop an empirical lagged-statistical September sea ice extent forecast, similar to that described by Kapsch et al. (2014). If so, the addition of surface-based observatories in other locations may further improve such a forecast (e.g., Uttal et al. 2016). Future research will incorporate stations representing other arctic sectors, such as northern Canada and Siberia, to assess the causes of the observed relationships and establish more spatially robust statistical links with the sea ice and variability in atmospheric transport of moisture and energy to and from the Arctic. This work should also include a focus on regional rather than Arctic-wide applications (e.g., Stone et al. 2005). Of particular priority should be hybrid approaches that leverage both direct observations made at the surface, spatial datasets such as reanalyses or satellite products, and climate indices. These steps are needed to validate and refine the conceptual model. Preconditioning is now identified with respect to memory in sea ice (e.g., Blanchard-Wrigglesworth et al. 2011), surface physical properties (e.g., Stone et al. 2005; Schröder et al. 2014), and cloud, temperature, and humidity anomalies (e.g., Kapsch et al. 2013; Choi et al. 2014; Liu and Key 2014; Wang et al. 2015; Letterly et al. 2016). Forecast improvement will likely benefit from leveraging these diverse mechanisms together.

Acknowledgments. This research is supported by the Arctic Research Program (ARP) of the National Oceanic and Atmospheric Administration (NOAA) Climate Program Office (CPO). M.S. was supported by the U.S. Department of Energy (DOE) Atmospheric System Research Program (DE-SC0011918). Measurements of broadband radiative fluxes used in this study are from stations operated by the NOAA Global Monitoring Division (GMD; available online at http:// www.esrl.noaa.gov/gmd/dv/data/) and the U.S. Department of Energy Atmospheric Radiation Measurement (ARM) Program (available online at http://www. arm.gov). National Snow and Ice Data Center (NSIDC) sea ice index data are available online (Fetterer et al. 2002). The Hadley Centre Sea Ice and Sea Surface Temperature (HadISST) dataset is available online at http://www.metoffice.gov.uk/hadobs/hadisst/. The European Centre for Medium-Range Weather Forecasts (ECMWF) interim reanalysis is available online at http://apps.ecmwf.int/datasets/. We are appreciative of the input from members of the International Arctic Systems for Observing the Atmosphere (IASOA) Radiation Working Group (http://iasoa.org).

\section{REFERENCES}

Bennartz, R., and Coauthors, 2013: July 2012 Greenland melt extent enhanced by low-level liquid clouds. Nature, 496, 83-86, doi:10.1038/nature12002.

Blanchard-Wrigglesworth, E., K. C. Armour, C. M. Bitz, and E. DeWeaver, 2011: Persistence and predictability of arctic sea ice in a GCM ensemble and observations. J. Climate, 24, 231250, doi:10.1175/2010JCLI3775.1.

Bromwich, D. H., R. L. Fogt, K. I. Hodges, and J. E. Walsh, 2007: A tropospheric assessment of the ERA-40, NCEP, and JRA-25 global reanalyses in the polar regions. J. Geophys. Res., $\mathbf{1 1 2}$ D10111, doi:10.1029/2006JD007859.

Cavalieri, D. J., and C. L. Parkinson, 2012: Arctic sea ice variability and trends, 1979-2010. Cryosphere, 6, 881-889, doi:10.5194/tc-6-881-2012.

Cesana, G., J. E. Kay, H. Chepfer, J. M. English, and G. de Boer, 2012: Ubiquitous low-level liquid-containing arctic clouds: New observations and climate model constraints from CALIPSO-GOCCP. Geophys. Res. Lett., 39, L20804, doi:10.1029/2012GL053385.

Choi, Y.-S., B.-M. Kim, S.-K. Hur, S.-J. Kim, J.-H. Kim, and C.-H. Ho, 2014: Connecting early summer cloud-controlled sunlight and later summer sea ice in the Arctic. J. Geophys. Res. Atmos., 119, 11 087-11 099, doi:10.1002/2014JD022013.

Cox, C. J., V. P. Walden, and P. M. Rowe, 2012: A comparison of atmospheric conditions at Eureka, Canada, and Barrow, Alaska (2006-2008). J. Geophys. Res., 117, D12204, doi:10.1029/2011JD017164.

,,- G. P. Compo, P. M. Rowe, M. D. Shupe, and K. Steffen, 2014: Downwelling longwave flux over Summit, Greenland, 2010-2012: Analysis of surface-based observations and evaluation of ERA-Interim using wavelets. J. Geophys. Res. Atmos., 119, 12 317-12 337, doi:10.1002/2014JD021975.

,,-- P. M. Rowe, and M. D. Shupe, 2015: Humidity trends imply increased sensitivity to clouds in a warming Arctic. Nat. Commun., 6, 10117, doi:10.1038/ncomms10117.

Curry, J. A., and E. E. Ebert, 1992: Annual cycle of radiation fluxes over the Arctic Ocean: Sensitivity of cloud optical properties. J. Climate, 5, 1267-1280, doi:10.1175/1520-0442(1992)005<1267: ACORFO $>2.0 . \mathrm{CO} ; 2$.

_ W. W. Rossow, D. Randall, and J. L. Schramm, 1996: Overview of arctic cloud and radiation characteristics. J. Climate, 9, 1731-1764, doi:10.1175/1520-0442(1996)009<1731:OOACAR>2.0.CO;2.

Dee, D. P., and Coauthors, 2011: The ERA-Interim reanalysis: Configuration and performance of the data analysis system. Quart. J. Roy. Meteor. Soc., 137, 553-597, doi:10.1002/qj.828.

Dong, X., and G. G. Mace, 2003: Arctic stratus cloud properties and radiative forcing derived from ground-based data collected at Barrow, Alaska. J. Climate, 16, 445-461, doi:10.1175/ 1520-0442(2003)016<0445:ASCPAR > 2.0.CO;2. 
— B. Xi, K. Crosby, C. N. Long, R. S. Stone, and M. D. Shupe, 2010: A 10 year climatology of arctic cloud fraction and radiative forcing at Barrow, Alaska. J. Geophys. Res., 115, D17212, doi:10.1029/2009JD013489.

- B. J. Zib, B. Xi, R. Stanfield, Y. Deng, X. Zhang, B. Lin, and C. N. Long, 2014: Critical mechanisms for the formation of extreme arctic sea-ice extent in the summers of 2007 and 1996. Climate Dyn., 43, 53-70, doi:10.1007/s00382-013-1920-8.

Durr, B., and R. Philipona, 2004: Automatic cloud amount detection by surface downward longwave radiation measurements. J. Geophys. Res., 109, D05201, doi:10.1029/2003JD004182.

Dutton, E. G., J. J. Michalsky, T. Stoffel, B. W. Forgan, J. Hickey, D. W. Nelson, T. L. Alberta, and I. Reda, 2001: Measurement of broadband diffuse solar irradiance using current commercial instrumentation with a correction for thermal offset errors. J. Atmos. Oceanic Technol., 18, 297-314, doi:10.1175/ 1520-0426(2001)018<0297:MOBDSI >2.0.CO;2.

Fetterer, F., K. Knowles, W. Meier, and M. Savoie, 2002: Sea ice index, version 1 (1993 to 2014). National Snow and Ice Data Center, accessed December 2014, doi:10.7265/N5QJ7F7W.

Francis, J. A., and E. Hunter, 2007: Changes in the fabric of the Arctic's greenhouse blanket. Environ. Res. Lett., 2, 045011, doi:10.1088/1748-9326/2/4/045011.

Graversen, R. G., T. Mauritsen, S. Drijfhout, M. Tjernström, and S. Mårtensson, 2011: Warm winds from the Pacific caused extensive arctic sea-ice melt in summer 2007. Climate Dyn., 36, 2103-2112, doi:10.1007/s00382-010-0809-z.

Hezel, P. J., X. Zhang, C. M. Bitz, B. P. Kelly, and F. Massonnet, 2012: Projected decline in spring snow depth on Arctic sea ice caused by progressively later autumn open ocean freeze-up this century. Geophys. Res. Lett., 39, L17505, doi:10.1029/ 2012 GL052794.

Intrieri, J. M., C. W. Fairall, M. D. Shupe, P. O. G. Persson, E. L Andreas, P. Guest, and R. M. Moritz, 2002: An annual cycle of arctic surface cloud forcing at SHEBA. J. Geophys. Res., 107, 8039, doi:10.1029/2000JC000439.

Kapsch, M.-L., R. G. Graversen, and M. Tjernström, 2013: Springtime atmospheric energy transport and the control of arctic summer sea-ice extent. Nat. Climate Change, 3, 744-748, doi:10.1038/nclimate1884.

,,-- T. Economou, and M. Tjernström, 2014: The importance of spring atmospheric conditions for predictions of the arctic summer sea ice extent. Geophys. Res. Lett., 41, 52885296, doi:10.1002/2014GL060826.

Kay, J. E., and T. L'Ecuyer, 2013: Observational constraints on Arctic Ocean clouds and radiative fluxes during the early 21 st century. J. Geophys. Res. Atmos., 118, 7219-7236, doi:10.1002/jgrd.50489.

— - - A. Gettelman, G. Stephens, and C. O'Dell, 2008: The contribution of cloud and radiation anomalies to the 2007 arctic sea ice extent minimum. Geophys. Res. Lett., 35, L08503, doi:10.1029/2008GL033451.

Kwok, R., and N. Untersteiner, 2011: The thinning of arctic sea ice. Phys. Today, 64, 36-41, doi:10.1063/1.3580491.

Letterly, A., J. Key, and Y. Liu, 2016: The influence of winter cloud on summer sea ice in the Arctic, 1983-2013. J. Geophys. Res. Atmos., 121, 2178-2187, doi:10.1002/2015JD024316.

Lindsay, R., M. Wensnahan, A. Schweiger, and J. Zhang, 2014: Evaluation of seven different atmospheric reanalysis products in the Arctic. J. Climate, 27, 2588-2606, doi:10.1175/ JCLI-D-13-00014.1.

Liu, Y., and J. Key, 2014: Less winter cloud aids summer 2013 arctic sea ice return from 2012 minimum. Environ. Res. Lett., 9, 044002, doi:10.1088/1748-9326/9/4/044002.
Long, C. N., 2005: Accounting for circumsolar and horizon cloud determination errors in ski image inferral of sky cover. Proc. 15th Atmospheric Radiation Measurement Science Team Meeting, Daytona Beach, FL, Department of Energy ARM Program, 7 pp. [Available online at https://www.arm.gov/ publications/proceedings/conf15/extended_abs/long_cn2.pdf.]

, and T. P. Ackerman, 2000: Identification of clear skies from broadband pyranometer measurements and calculation of downwelling shortwave cloud effects. J. Geophys. Res., 105, 15 609-15 626, doi:10.1029/2000JD900077.

- and Y. Shi, 2008: An automated quality assessment and control algorithm for surface radiation measurements. Open Atmos. Sci. J., 2, 23-37, doi:10.2174/1874282300802010023.

— , and D. D. Turner, 2008: A method for continuous estimation of clear-sky downwelling longwave radiative flux developed using ARM surface measurements. Geophys. Res. Lett., 113, D18206, doi:10.1029/2008JD009936.

— T. T. Ackerman, K. L. Gaustad, and J. N. S. Cole, 2006: Estimation of fractional sky cover from broadband shortwave radiometer measurements. J. Geophys. Res., 111, D11204, doi:10.1029/2005JD006475.

Matsui, N., and Coauthors, 2012: Evaluation of arctic broadband surface radiation measurements. Atmos. Meas. Tech., 5, 429438, doi:10.5194/amt-5-429-2012.

McFarlane, S. A., C. N. Long, and J. Flaherty, 2013: A climatology of surface cloud radiative effects at the ARM tropical western Pacific sites. J. Appl. Meteor. Climatol., 52, 996-1012, doi:10.1175/JAMC-D-12-0189.1.

Miller, N. B., M. D. Shupe, C. J. Cox, V. P. Walden, D. D. Turner, and K. Steffen, 2015: Cloud radiative forcing at Summit, Greenland. J. Climate, 28, 6267-6280, doi:10.1175/ JCLI-D-15-0076.1.

Ohmura, A., and Coauthors, 1998: Baseline Surface Radiation Network (BSRN/WCRP): New precision radiometry for climate research. Bull. Amer. Meteor. Soc., 79, 2115-2136, doi:10.1175/1520-0477(1998)079<2115:BSRNBW>2.0.CO;2.

Overland, J. A., and M. Wang, 2010: Large-scale atmospheric circulation changes are associated with recent loss of arctic sea ice. Tellus, 62A, 1-9, doi:10.1111/j.1600-0870.2009.00421.x.

Parkinson, C. L., and J. C. Comiso, 2013: On the 2012 record low arctic sea ice cover: Combined impact of preconditioning and an August storm. Geophys. Res. Lett., 40, 1356-1361, doi:10.1002/grl.50349.

Persson, P. Ola. G., 2012: Onset and end of the summer melt season over sea ice: Thermal structure and surface perspective from SHEBA. Climate Dyn., 39, 1349-1371, doi:10.1007/ s00382-011-1196-9.

, T. Uttal, J. M. Intrieri, C. W. Fairall, E. L Andreas, and P. S. Guest, 1999: Observations of large thermal transitions during the arctic night from a suite of sensors at SHEBA. Preprints, Third Symp. on Integrated Observing Systems, Dallas, TX, Amer. Meteor. Soc., J5.3.

Pithan, F., B. Medeiros, and T. Mauritson, 2014: Mixed-phase clouds cause climate model biases in arctic wintertime temperature inversions. Climate Dyn., 43, 289-303, doi:10.1007/ s00382-013-1964-9.

Ramanathan, V., R. D. Cess, E. F. Harrison, P. Minnis, B. R. Barkstrom, E. Ahmad, and D. Hartman, 1989: Cloudradiative forcing and climate: Results from the Earth Radiation Budget Experiment. Science, 243, 57-63, doi:10.1126/ science.243.4887.57.

Rayner, N. A., D. E. Parker, E. B. Horton, C. K. Folland, L. V. Alexander, D. P. Rowell, E. C. Kent, and A. Kaplan, 2003: 
Global analyses of sea surface temperature, sea ice, and night marine air temperature since the late nineteenth century. J. Geophys. Res., 108, 4407, doi:10.1029/2002JD002670.

Riihelä, A., T. Manninen, and V. Laine, 2013: Observed changes in the albedo of the Arctic sea-ice zone for the period 1982-2009. Nat. Climate Change, 3, 895-898, doi:10.1038/nclimate1963.

Schröder, D., D. L. Feltham, D. Flocco, and M. Tsamados, 2014: September arctic sea-ice minimum predicted by spring meltpond fraction. Nat. Climate Change, 4, 353-357, doi:10.1038/ nclimate2203.

Shupe, M. D., 2011: Clouds at arctic atmospheric observatories. Part II: Thermodynamic phase characteristics. J. Appl. Meteor. Climatol., 50, 645-661, doi:10.1175/2010JAMC2468.1.

- and J. M. Intrieri, 2004: Cloud radiative forcing of the arctic surface: The influence of cloud properties, surface albedo, and solar zenith angle. J. Climate, 17, 616-628, doi:10.1175/ 1520-0442(2004)017<0616:CRFOTA > 2.0.CO;2.

—, V. P. Walden, E. Eloranta, T. Uttal, J. R. Campbell, S. M. Startweather, and M. Shiobara, 2011: Clouds at arctic atmospheric observatories. Part I: Occurrence and macrophysical properties. J. Appl. Meteor. Climatol., 50, 626-644, doi:10.1175/ 2010JAMC2467.1.

Simmons, J. A., and D. M. Burridge, 1981: An energy and angularmomentum conserving vertical finite-difference scheme and hybrid vertical coordinates. Mon. Wea. Rev., 109, 758-766, doi:10.1175/1520-0493(1981)109<0758:AEAAMC >2.0.CO;2.

Stone, R. S., E. G. Dutton, J. M. Harris, and D. Longenecker, 2002: Earlier spring snowmelt in northern Alaska as an indicator of climate change. J. Geophys. Res., 107, 4089, doi:10.1029/ 2000JD000286.

- D. Douglas, G. Belchansky, and S. Drobot, 2005: Correlated declines in Pacific arctic snow and sea ice cover. Arct. Res. U. S., 19, 18-25.

Stroeve, J., L. C. Hamilton, C. M. Bitz, and E. BlanchardWrigglesworth, 2014: Predicting September sea ice: Ensemble skill of the SEARCH sea ice outlook 2008-2013. Geophys. Res. Lett., 41, 2411-2418, doi:10.1002/2014GL059388.
Tjernström, M., J. Sedlar, and M. D. Shupe, 2008: How well do regional climate models reproduce radiation and clouds in the Arctic? An evaluation of ARCMIP simulations. J. Appl. Meteor. Climatol., 47, 2405-2422, doi:10.1175/ 2008JAMC1845.1.

Uttal, T., and Coauthors, 2016: International arctic systems for observing the atmosphere: An International Polar Year legacy consortium. Bull. Amer. Meteor. Soc., 97, 1033-1056, doi:10.1175/BAMS-D-14-00145.1.

Van Tricht, K., and Coauthors, 2016: Clouds enhance Greenland ice sheet meltwater runoff. Nat. Commun., 7, 10266, doi:10.1038/ ncomms10266.

Walsh, J. E., W. L. Chapman, and D. H. Portis, 2009: Arctic cloud fraction and radiative fluxes in atmospheric reanalyses. J. Climate, 22, 2316-2334, doi:10.1175/2008JCLI2213.1.

Wang, T., S. Peng, C. Ottlé, and P. Ciais, 2015: Spring snow cover deficit controlled by interseasonal variability of surface energy fluxes. Environ. Res. Lett., 10, 024018, doi:10.1088/1748-9326/ 10/2/024018.

Wesslén, C., M. Tjernström, D. H. Bromwich, G. de Boer, A. M. L. Ekman, L.-S. Bai, and S.-H. Wang, 2014: The arctic summer atmosphere: An evaluation of reanalyses using ASCOS data. Atmos. Chem. Phys., 14, 2605-2624, doi:10.5194/ acp-14-2605-2014.

Younkin, K., and C. N. Long, 2003: Improved correction of IR loss in diffuse shortwave measurements: An ARM value-added product. Pacific Northwest National Laboratory Tech. Rep. DOE/SC-ARM/TR-009, 50 pp. [Available online at http://www. arm.gov/publications/tech_reports/arm-tr-009.pdf?id=596.]

Zib, B. J., X. Dong, B. Xi, and A. Kennedy, 2012: Evaluation and intercomparison of cloud fraction and radiative fluxes in recent reanalyses over the Arctic using BSRN surface observations. J. Climate, 25, 2291-2305, doi:10.1175/JCLI-D-11-00147.1.

Zygmuntowska, M., T. Mauritsen, J. Quass, and L. Kalescke, 2012: Arctic clouds and surface radiation-A critical comparison of satellite retrievals and the ERA-Interim reanalysis. Atmos. Chem. Phys., 12, 6667-6677, doi:10.5194/acp-12-6667-2012. 